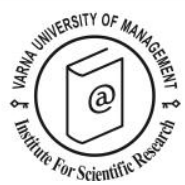

\title{
Scott, N., Gao J., and Ma, Jianyu (Eds.). Visitor Experience Design. Oxfordshire, UK: CAB International.
}

\author{
ISBN: 978-1-78639-189-6. (2017). 283 pp, English.
}

\author{
Reviewed by Tina Šegota ${ }^{1}$
}

Received: 31/01/2018

\begin{abstract}
${ }^{1}$ Department of Marketing, Events and Tourism, Business School, University of Greenwich, Old Royal Naval College, Park Row, London SE10 9LS, United Kingdom; Tel. +44 (0)20 8331 9034; t.segota@greenwich.ac.uk
\end{abstract}

(C) 2018 Varna University of Management. All rights reserved

Citation Scott, N., Gao J., and Ma, Jianyu (Eds.). Visitor Experience Design. Oxfordshire, UK: CAB International. ISBN: 978-1-78639-189-6. (2017). 283 pp, English. Reviewed by Tina Šegota, European Journal of Tourism Research 19, pp. 156-159

"Everything a tourist goes through at a destination is an experience, be it behavioural or perceptual, cognitive or emotional, expressed or implied" (Oh et al., 2007, p. 120, cited in Jiang, 2017, p. 53). Tourist experience is not limited to what happens during travel, but it also encompasses before and after travel emotions and behaviour. For many years, the research on visitor experience has been discussed through managerial and/or behavioural lenses. Such research, in its own right, discussed the creation and delivery of memorable and exciting visitor experience in tourism, but it majorly ignored the way visitors perceive those experiences. In this sense, visitors' feelings, thoughts, perceptions, etc. were supressed within a black box that has been very rarely opened and explored, making a visitor 'persona non grata'. Visitor Experience Design illuminates the black box by making the way the visitor thinks about the experience the centrepiece of discussion. Its originality is in opening the black box using psychological lenses, and thus providing insights into pre-stage, on-stage and poststage experience that draws from recent findings from cognitive psychology, cognitive science and neuroscience.

In general, this book is very well thoughtthrough and its framework more than excellently addresses the challenge of developing a comprehensive piece about tourism experience. The book consists of six conceptual parts, comprising a total of 17 chapters. Part One sets the stage for the creation of memorable experiences by delivering theories and frameworks on the intercepts of tourism experience and psychology. In the first chapter, the editors of the book set a profound introduction into the conceptualisation of tourism experience by defining experience in general and defining tourist experience and designed tourist experience in particular. They also serve with a rather unusual visual chapter structure this is well-worth of praise since, as mentioned before, "challenging" would be an understatement for comprehensively 
addressing tourism experience, its multiple stages, and elements within an enjoyable academic reading. In the second chapter, Larsen and co-authors justifiably critique tourism research as "sometimes problematic and sometimes confusing and sometimes both" (p. 13) to stress why psychology could stimulate tourist experience studies. They also provided two examples of psychological tourism studies as a "know-how" for those interested in studying "the minds and behaviours of tourists" (p. 26). The third chapter serves with a review of the history, disciplinary approaches, types and theoretical models of tourism experience. The focus is on theoretical developments rather than methodology, which has been touched upon in the former chapter.

Consumer Inputs in the Pre-experience Stage is the second conceptual part of this book, which unifies two chapters that explain and discuss the role of motivation and decision making in tourist experience. Shan Jiang, the author of the fourth chapter, explores experience and motivation using means-end chain theory. The means-end chain theory represents an approach that aids in identifying "the motivational drivers influencing tourist experience" (p. 53). Moreover, the author delivers a conceptual framework for research and development of tourism experience to explore "how destination attributes deliver a tourist their preferred experience and satisfy their needs at the value of travel" (ibid). The fifth chapter touches upon a number of key concepts that are important for understanding holiday decision making - emotion, memory, perception, retrospection, and fantasy. It discusses the concepts through lenses of the current findings from cognitive psychology and neuroscience to bring theoretical and conceptual rigour to research on hedonic consumption experiences in tourism.

The third part of the book consists of five chapter that discusses different elements of the on-site tourist experience. They discuss either the visitors' emotion, motivation, meaning, and value or a methodology for measuring in situ experiences. Hence, the authors of Chapter 6 illustrate the co-creation of on-site experiences and its influence on stimulating attention and increased memorability in a case study of the animalbased tourism experience in Portugal. Following is the chapter on the elicitation of emotions, embedded in the theoretical framework of the cognitive appraisal theory. The author highlights five different appraisal dimensions - goal congruence, agency, certainty, novelty, and dimensions affecting emotional intensity, and further discusses how these could aid in understanding how consumers interpret their experiences and subjectively elicit specific emotions. But when it comes to emotions, it is very difficult to measure them. This has been of particular interest to the authors in Chapters 8 and 9. In the former, the self-report measures for measuring visitors' emotional responses were rightfully criticized and hence the psychophysiological measurements of emotions have been introduced; namely, electro-dermal activity, facial electromyography, eye tracking and heart rate. Contrary to what is expected, the authors concluded that the self-report methods are not to be completely discarded, yet "use of both the self-reporting method and psychophysiological techniques is an important direction for future tourism research" (p. 126). In Chapter 9, Wang, Liu, and Sparks broadened the discussion of the use of alternative measurements to the selfreporting methods to eye tracking, the experience sampling method and photo elicitation. The authors see them as both "powerful yet underused methods for investigating tourist experience" (p. 137), and thus, for each they present the definition, the applicability to various research situations and the key issues to consider in the implementation of the method. The last chapter discusses the typology of consumer value and explores the linkage between different types of value for on-site tourism experiences. Customer value consists of experiential, symbolic, functional, and cost value, which were shown to be interrelated and diversely linked to each other. For example, the study showed that there is a hierarchical link between the functional value 
and experiential and symbolic value, where the latter two require the existence of the former. In this sense, the authors explain that "without functional value, tourists were not willing to be involved in an experienced process and did not perceive any other value from that process" (p. 166).

Well-being, satisfaction, destination attributes, and sharing are keywords that describe the part of the book that discusses some outcomes of tourism experience. In Chapter 11 , well-being benefits related to the mental state of mindfulness have been identified, providing a new direction in understanding therapeutic functions of tourist experiences. The next chapter, Motivational Satisfaction and Emotional Outcomes from Experiences, represents a theoretical piece where the author demonstrated a non-exclusive relationship between emotions and satisfaction, and subsequently behavioural intentions. Here, satisfaction is perceived as a positive emotion, derived from the fulfilment of tourists' needs, which ultimately leads to behavioural intentions no practitioner could ignore - loyalty, revisit, positive word-ofmouth communication etc. Chapter 13 brings to reader's attention specific attributes perceived by tourists in a destination, their interconnectedness and the role each attribute plays in creating holistic destination experience by tourists. Empirical evidence is based in a Chinese water town of Zhouzhuang, which have also been used in chapter ten. As a reminder, chapter 10 explores the linkage between experiential, symbolic, functional, and cost value that are formed by different destination attributes. And it is the latter that this chapter brings forward. Hence, it is advisable to first read chapter 13 in order to better understand each set of attributes - atmosphere, interaction, memorabilia, and service, and then go back to chapter 10 in order to better understand the linkages between different values. The last chapter of this theoretical frame, authored by $\mathrm{Wu}$ and $\mathrm{Li}$, explores the gaps in the information sharing literature in order to highlight five new directions for future research on tourism experience sharing: cross-cultural and intercultural extensions, 158 social transmission and virality in experience sharing, motivational drivers for experience sharing, contextual influences, and the consequential impact of tourism experience sharing.

The last two parts of the book bring to reader's attention two very interesting experience design cases and the conclusion. The first case study examines decision making in tourism in relation to slow food consumption. Lee concluded that members of the Slow Food community do not travel for food, but once they arrive at the destination, they remain faithful to the Slow Food values. In this sense, "not all foodies travel for food", meaning that there is a clear distinction of decision making when choosing the destination and when choosing activities upon arrival at the destination. The second case study places international travel bloggers and their perceptions of the Trinidad Carnival experiences into the spotlight. With the discussion of bloggers' sensory and affective perceptions, Holder and Scott provide with insights that might be of great interest to experiential marketers and tourism product developers. In the concluding chapter, the editors remind us once again why there is lack of cognitive psychology in the tourism literature. To stress, it is useful to be reminded that we, academics, need to be bolder in answering questions that deal with how tourists experience tourism experiences. The sophisticated way in which editors encourage researchers to "open the black box of the /tourist's/ brain" (p. 267) is by embracing cognitive psychology, both in its theoretical and methodological rigours. And this is one of the main values of the book; giving to academics alternative lenses to challenge the established understanding of tourism experiences, providing students and early career researchers with gaps and future research avenues in tourism experience literature, which might as well become their entry-ticket to the academic discussion, and demonstrating to practitioners that tourism experience design needs to be approached holistically, taking into account before, during and after travel emotions and behaviours. 
Scott, N., Gao J., and Ma, Jianyu (Eds.). Visitor Experience Design. Oxfordshire, UK: CAB International. ISBN: 978-1-78639189-6. (2017). 283 pp, English. Reviewed by Tina Šegota, European Journal of Tourism Research 19, pp. 156-159

\section{References}

Jiang, S. (2017). Exploring Experience and Motivation Using Means-end Chain Theory. In N. Scott, J. Gao, \& J. Ma. (Eds.), Visitor Experience Design (pp. 53-67). Oxfordshire, UK: CAB International.
Oh, H. M., Fiore, A. M., \& Jeoung, M. Y. (2007). Measuring experience economy concepts: tourism applications. Journal of Travel Research 46, 119-131. 